\title{
The impact of urbanization and institutions of higher education on Houston Texas' Third Ward Community
}

\author{
AKPAN I. AKPAN \\ Department of Urban Planning and Environmental Policy, Texas Southern University, 3100 Cleburne Avenue, Houston, Texas 77004, USA. \\ Tel.: 713-313-7398; Fax: 713-313-7447; E-mail:akpan_ai@tsu.edu
}

\begin{abstract}
University towns are influenced by the features of urbanization and impact greatly on the health of the inhabitants. This paper evaluates the impacts of urbanization on the Third Ward communities that are located within Texas Southern University and the University of Houston. The paper further assesses how characteristics of the urban environment may have affected the population health. The historical background of the Third Ward Houston Texas is first reviewed to determine the extent to which urbanization and the presence of universities have impacted on the quality of life of the residents. The overall effects of urbanization are reviewed using all the available literature with broad emphasis on the physical, and social environments, and access to health and social services. Irrespective of the presence of universities and colleges, the surrounding neighborhood communities of the Third Ward Houston continue to face formidable historic challenges to improving public health and general quality of life. Although, urbanization has brought about reinvestment initiatives, changing demographics, and growth creating changes that offer new opportunities for improving health while requiring that health systems be adapted to residents' health needs, however, the communities remain stagnant and unique. Ultimately, the key factors affecting the quality of life in the Third Ward communities are the physical environment, the social environment, and access to health and social services. Overall, the neighborhood communities of the Third Ward do not seem to respond positively to developmental influence of the universities and colleges and are negatively impacted by urbanization. It is suggested that improvement in the Third Ward areas should require setting local, state, and national agendas for progress. Therefore, certain priorities must be put in place namely, development must reorient around the educational and population dynamics, including cultural diversity, and the growing numbers of elderly. @JASEM
\end{abstract}

Urbanization is one of the most important demographic shifts worldwide during the past century and represents a substantial change from how most of the world's population has lived for the past several thousand years (Galea \& Vlahov, 2005). A majority of the world's population will live in urban areas by 2007. Urban environments have been linked to a range of human health issues, and as the pace of urbanization accelerates, new challenges arise to characterize these environments, and to understand their positive and negative implications for health (McDade \& Adair, 2001). The most rapidly urbanizing cities are in less-wealthy nations, and the pace of growth varies among regions (Vlahov \& Galea, 2002). Nearly half the world's population now lives in urban settlements. Cities offer the lure of better employment, education, health care, and culture; and they contribute disproportionately to national economies. However, rapid and often unplanned urban growth is often associated with poverty, environmental degradation and population demands that outstrip service capacity (Moore et al., 2003). These conditions place human health at risk. Reliable urban health statistics are largely unavailable throughout the world. Disaggregated intra-urban health data, i.e., for different areas within a city, are even more rare. Data that are available indicate a range of urban health hazards and associated health risks: substandard housing, crowding, air pollution, insufficient or contaminated drinking water, inadequate sanitation and solid waste disposal services, vector-borne diseases, industrial waste, increased motor vehicle traffic, stress associated with poverty and unemployment, among others (Moore et al., 2003). Local and national governments and multilateral organizations are all grappling with the challenges of urbanization (Moore et al., 2003). Urban health risks and concerns involve many different sectors, including health, environment, housing, energy, transportation, urban planning, and others (Moore et al., 2003).

Fleischman \& Barondess (2004) reported that approximately $80 \%$ of Americans live in cities or immediately adjacent communities. Such urban environments are complex amalgams of people of disparate backgrounds, economic status, and expectations, with extraordinary disparities in health status and outcomes between groups just blocks apart. Urban health as a framing paradigm is of recent vintage and offers a perspective on health and disease that integrates clinical medicine and public health and draws on the social and political sciences to seek understanding of the impact of cities on the health of populations and individuals. Ironically, disparate outcomes and increased mortality among poor minority populations in cities are not primarily related to the consequences of the urban epidemics of drugs and violence but rather are due to the increased prevalence and severity of common diseases such as asthma, cardiovascular disease, diabetes, and kidney disease (Fleischman \& Barondess, 2004). Several factors may be responsible for such disparities, including stress, racism, and perceptions of 
deprivation, economic inequalities, and lack of access to quality health care. It is time for leaders in medical education and health care delivery to focus on the populations that surround their institutions in order to study urban health and meet the challenge of caring for all the residents of our cities (Fleischman \& Barondess, 2004).

Third Ward Community: Historical background : The Third Ward community is one of the most historic African American communities in Houston Texas. It is located within and around two wellknown universities namely, Texas Southern University and the University of Houston. The Greater Third Ward is approximately 8.3 square miles and it is located inside the 610 Loop and it encompasses the area south of the University of Houston to Old Spanish Trail with boundaries that are north to the Gulf Freeway, west to Fannin and east to the H.B. and T Railroad (Third Ward Development, 2004). There are twelve residential neighborhoods that lie within the Greater Third ward area. The majority of the population is mainly African American (79.15\%), Hispanics (10.40\%, and Whites (6.62\% approximately. Asians are only 2.07\% and the remaining $1.76 \%$ includes Native Americans and others (City of Houston).

Alabama street was used as an architectural dividing line for racial purposes in the years of Segregation. Black and Hispanic populations were located to the north of Alabama street. The housing was and still is mostly made from wood commonly called "row houses" or shotgun shacks and presently has turned into slum. South of Alabama Street was prominent Jewish neighborhood. The houses on the Jewish neighborhood were all brick houses, many of which are still standing to this day. During the time of desegregation, as Blacks became free to move south of Alabama, a major phenomenon called "White flight” took place in the Third ward. As blacks started to move into the neighborhood, Whites vacated. The neighborhood in itself suffered land value depreciation, as the Whites did not care to sell their properties at their rightful prices as long as they could get out and therefore sold them for anything.

The majority of the population is over 18 years of age with approximately $6.60 \%$ under 5 years of age. There are a wide variety of median household incomes in Greater third Ward. Generally, the median household income is approximately \$37,355. Approximately, one-third of the Greater Third Ward population lives in poverty and crime population statistics provided by the FBI showed a total of 187,751 cases in the year 2000. The neighborhoods differ a lot from each other, like the South End (Binz) neighborhood, which has banking facilities, museums, and medical facilities intermingling with older homes. In comparison to the Greater Third Ward neighborhood, the Third Ward Community lacks banks, big chain stores and has very modest wood frame houses, small corner stores and churches.

Policy Perspectives and implications: Two main policy implications are highlighted: the need for systematic and useful urban health statistics on a disaggregated, i.e., intra-urban, basis, and the need for more effective partnering across sectors. The humanitarian and economic imperative to create livable and sustainable cities must drive us to seek and successfully overcome challenges and capitalize on opportunities. Good urban planning and governance, exchange of best practice models and the determination and leadership of stakeholders across disciplines, sectors, communities and countries will be critical elements of success (Moore et al., 2003). A new 1996-97 report from the World Resources Institute, the UN Environmental Program, the UN Development Program, and the World Bank, describes a future with increased levels of urbanization that were reshaping the physical and social environment. Urbanization increased economic growth and environmental degradation. Three issues are particularly crucial to survival: the water supply, sanitation, and water resource management (World Resources Institute;UNEP, UNDP, 1996) . There is overcrowding and exposure to industrial wastes and air pollution. There is a need for policy reform, stronger institutions, and enlightened political leadership. Cities need to improve their environment and to strengthen local government and implement poverty reduction programs. Effective urban governance must accompany reform of urban policies. Community-based approaches are essential. Broad-based support is needed for changes in strategies and practices and for attainment of a more sustainable environment (World Resources Institute; UNEP, UNDP, 1996). Urbanization is probably the single most important demographic shift world-wide throughout the past and the new century and represents a sentinel change from how most of the world's population has lived for the past several thousand years (Galea et al., 2005). As urban living becomes the predominant social context for the majority of the world's population, the very ubiquity of urban living promises to shape health directly and to indirectly affect what we typically consider risk factors or determinants of population health. Although a growing body of research is exploring how characteristics of the urban environment may be associated with health (e.g. depression) and risk behaviors (e.g. exercise patterns), relatively little research has systematically assessed how the urban 
environment may affect drug use and misuse. A conceptual framework for considering how different characteristics of the urban environment (e.g. collective efficacy, the built environment) may be associated with drug use and misuse, summarize the existing empiric literature that substantiates elements of this framework, and identify potential directions for future research (Galea et al., 2005).

Environmental hazards and sanitation: An effective environmental sanitation program should encompass key features considered necessary for a primary health care (PHC) program such as availability, accessibility, affordability, acceptability, and practicability. Poor housing conditions give rise to stress, delinquency, and crime, as well as to helminthic and other parasitic infestations (Rotibi, 1992). Anderson et al. (2004) reported that the Public hospitals in the United States play a key role in urban health. In many metropolitan communities, public hospitals maintain the health care safety net. Most urban public hospitals have evolved to not only provide care for the indigent but also to serve their communities in other ways, including serving as major providers for tertiary services such as trauma and those that support homeland security; serving as the foundation for primary care services; continuing to train a significant number of physician, nurses, and other medical personnel; and providing laboratories for clinical medical research. Federal budget cuts such as those in the Balanced Budget Act of 1997, recent state budget deficits, competition for Medicaid Managed Care, and the growth in the number of uninsured have led to a decline in revenues among urban public hospitals. To be better stewards of scarce resources, public hospitals have moved to reduce inpatient demand by adopting prevention strategies that are aimed at addressing the determinants of health, the complex interactions among social and economic factors, the physical environment, and individual behavior. These factors contribute to health status and offer opportunities to intervene and improve community health. Urban public hospitals, to be successful in the next stage of their evolution, need to learn to manage the "inbetweens"--partnering with governmental and nongovernmental entities to identify and work together on common health and safety issues. If public hospitals engage the community successfully, building trust and establishing new capability and capacity, urban public hospitals will survive, evolve, and continue their tradition of service.

Environmental hazards in urban areas mainly affect low-income people--especially women, children, and migrants--the people who are least able to avoid the hazards and/or least able to deal with the illness or injury they cause. Poor people are priced out of safe, well located, well-serviced housing and land sites. Hazards include biological pathogens; chemical pollutants; scarce, over-priced, or poor quality natural resources; physical hazards; natural resource degradation; and national/global environmental degradation (Satterthwaite, 1993). These preventable health burdens cause disease, accidents, and premature death. Biological pathogens have the most serious impact on human health. Crowded conditions, poor sanitation, and inadequate water supplies, poor facilities for preparing and storing food, and inadequate hygiene contribute to biological pathogeninduced ill health. Common chemical pollutants in urban areas are lead, indoor air pollutants from fuel combustion, toxic/hazardous wastes, and ambient air pollution. A shortage of fresh water is often why some urban households do not have a safe and adequate water supply. Limited land in cities prevents the urban poor from growing their own crops or maintaining livestock. Common physical hazards in cities are traffic accidents; burns, scalds, and accidental fires and poisonings; falls; and floods (Satterthwaite, 1993). Overcrowding, poor building material, and settlements on dangerous sites (e.g., flood plains, steep hillsides, and dumps) are example of physical hazards. Noise, overcrowding, inappropriate design, and stresses contribute to the growing psychosocial health problems of many urban dwellers in developing countries, especially of adolescents and young adults. Poorer urban residents who begin or are included in initiatives to improve their neighborhoods are more likely to develop integrated responses to nonenvironmental and environmental problems and to make sure that environmental action programs meet local needs and realities (Satterthwaite, 1993).

Access to Health Care: Equity in access to health care is now accepted as a basic ethical principle for health development. The glaring inequalities in health suffered by poor people living in slums are a strong justification for urgent action. The problem is rapidly increasing (Tabibzadeh \& Liisberg, 1997). Weak administrative structures and limited resources will be the norm in many of these cities as populations grow rapidly and uncontrolled. In the shantytowns of developing countries, health hazards are associated with the prevailing poverty, lack of water and sanitation, and substandard housing; changes in living conditions and lifestyles; chronic diseases related to modernization; lung diseases; accidents; mental and psychosomatic disorders; and social instability, cultural and social alienation, and the social and mental ill-effects of degrading living conditions and extreme crowding (Tabibzadeh \& Liisberg, 1997). While urban health care absorbs the 
bulk of most national health budgets, up to $85 \%$ of those funds are spent on curative services delivered through large specialist hospitals located in the cities. Many people in the surrounding shantytowns and slums have no access to cities' services or do not use them because they do not respond to their needs. The health services, which are available, tend to be poorly managed. Political will can, however, lead to improved urban health (Tabibzadeh \& Liisberg, 1997). To promote health and well-being more effectively, it is important that the public health officers, urban planners, and policy decision-makers at national and local levels should promote understanding of the multi-dimensional nature of health disorders of citizens. (Lawrence, 1999). In the future, increasing numbers of people will be living in precarious socioeconomic conditions, which impede the achievement of health. Twenty-five years ago, it was estimated that from 4.4 billion that the world's population would have increased to 6.2 billion by the year 2000 (Rossi-espagnet, 1983). The urban population would have increased from 1.8 to 3.2 billion during the same period. The rapid and often uncontrollable demographic growth of cities, stimulates the demand for resources, intensifies their utilization and creates an intolerable pressure on the urban infrastructure and physical environment (Rossi-espagnet, 1983).

The study of urban health considers how characteristics of the urban environment may affect population health. The key factors affecting health in cities can be considered within three broad themes: the physical environment, the social environment, and access to health and social services (Galea \& Vlahov, 2005). There are few data linking features of cities to the health of populations. Features of the urban environment that affect health and well-being: urbanization and urbanicity. Most of the important factors that affect health can be considered within three broad themes: the social environment, the physical environment, and access to health and social services (Vlahov \& Galea, 2002; (Vlahov et al., 2004). Modified from Vlahov et al. (2004), it is important to ask what specific features of university towns are causally related to health, the extent to which these features are unique to a particular university town or are different between university towns, and ultimately, to what extent these features of the university town are modifiable in order to allow interventions that can improve the health of urban populations.

Unauthorized squatter settlements and health implications: Urbanization gives rise to creation of unauthorized squatter settlements on the peripheries of large cities and these settlers share a low standard of housing resulting from lack of employment and low income (Schteingart \& Saenz, 1991). Very often large households are crowded into poor quality structures with no running water or sewage disposal. Health consequences are serious. Residents of squatter settlements generally fall below the rest of the urban population in health indicators. Settlers in these makeshift communities all tend to be disadvantaged, but there are significant differences in the health and living conditions of different lowincome zones on the urban periphery (Schteingart \& Saenz, 1991). Social variables affecting health include demographic and socioeconomic characteristics of families. It must also be remembered that conditions of the physical and social habitat are mediated by social practices such as hygienic habits, diet, use of medications, and reproductive patterns (Schteingart \& Saenz, 1991). The social determinants of health and environmental health promotion that include the conduction of sound scientific research on connections between the built environment and health, namely: (1) the necessity of dealing with the possible health consequences of myriad public and private sector activities; (2) the lack of valid and reliable indicators of the built environment to monitor the health effects of urban planning and policy decisions, especially with regard to land use mix; and (3) the growth of the "megalopolis" or "super urban region" that requires analysis of health effects across state lines and in circumscribed areas within multiple states (Northridge et al., 2003).

Contamination of drinking water: Pathogenic contamination of drinking water poses the most significant health risk to humans, and there have been countless numbers of disease outbreaks and poisonings throughout history resulting from exposure to untreated or poorly treated drinking water (Ritter et al., 2002). However, significant risks to human health may also result from exposure to nonpathogenic, toxic contaminants that are often globally ubiquitous in waters from which drinking water is derived. In assessing the relative risk of toxic contaminants in drinking water to humans, the major sources of contaminants from anthropogenic activities to aquatic surface and groundwater and the pathways along which these contaminants move to become incorporated into drinking water supplies should be considered as priorities (Ritter et al., 2002). The point source and non-point-source pollution should be identified and corrected with urgency. Point-source pollution originates from discrete sources whose inputs into aquatic systems can often be defined in a spatially explicit manner. Examples of point-source pollution include industrial effluents (pulp and paper mills, steel plants, food processing 
plants), municipal sewage treatment plants and combined sewage-storm-water overflows, resource extraction (mining), and land disposal sites (landfill sites, industrial impoundments). Non-point-source pollution, in contrast, originates from poorly defined, diffuse sources that typically occur over broad geographical scales (Ritter et al., 2002). Examples of non-point-source pollution include agricultural runoff (pesticides, pathogens, and fertilizers), storm-water and urban runoff, and atmospheric deposition (wet and dry deposition of persistent organic pollutants such as polychlorinated biphenyls [PCBs] and mercury) (Ritter et al., 2002). Ezzati et al. (2005) proposed a basic framework that is probably suitable for development of indicators of exposure to environmental health risks that would facilitate the (a) assessment of the health effects of risk factors, (b) design and evaluation of interventions and programs to deliver the interventions, and (c) appraisal and quantification of inequalities in health effects of risk factors, and benefits of intervention programs and policies. Specific emphasis is put on the features of environmental risks that should guide the choice of indicators, in particular the interactions of technology, the environment, and human behavior in determining exposure (Ezzati et al., 2005).

To achieve its health goals, the United States must reduce the disproportionate burden of illness and poor health borne by urban populations (Freudenberg, 2000). In the 20th century, patterns of immigration and migration, changes in the global economy, increases in income inequality, and more federal support for sub urbanization have made it increasingly difficult for cities to protect the health of all residents. In the last 25 years, epidemics of human immunodeficiency virus infections and substance abuse and increases in homelessness, lack of health insurance, rates of violence, and concentrations of certain pollutants have also damaged the health of urban residents (Freudenberg, 2000). Integration of lessons from human rights, church- and faith-based social action, community economic development, youth development, and the new social movements should help to revitalize the historic mission of public health, contribute to creating healthier cities, and better achieve national health objectives (Freudenberg, 2000). Thus, the urban public health department should coordinate efforts to surmount the hurdles and provides the venue for analysis, development, and employment of successful strategies (Guerra \& Crockett, 2004).

One of the main characteristics of urbanization is the very rapid increase in population movement from rural to urban centers leading to changing population structure, composition and lifestyles in the cities and its fringes. As consequently, the urban concentrates are faced with several social and socio-economic problems (Talib \& Agus, 1992; Mishra, 1996). Rural poverty has pushed villagers to the cities resulting in public health and social problems that lower the quality of life. Communicable diseases among the urban poor coexist with non-communicable diseases among the comparatively affluent. Problems of pollution, crime and chronic morbidity increase (Mutatkar, 1995).

The presence of the universities in the Third Ward should make a difference in the livability of surrounding neighborhoods and the overall health of the families it serves (McAvoy et al., 2004). Robust relationships between greenness change and demographic factors associated with urban decay (population decline, an increase in poverty level, and an increase in vacant units) are found. It is concluded that vegetation trends could be used as indicators of urban socioeconomic changes (Emmanuel, 1997).

Transportation systems: Although, there is a great improvement in transport systems especially by the Metro Services, there remains a problem of inefficient pedestrian and cycling aspects of land use. Saelens et al. (2003) reported that research in transportation, urban design, and planning has examined associations between physical environment variables and individuals' walking and cycling for transport. Constructs, methods, and findings from these fields can be applied by physical activity and health researchers to improve understanding of environmental influences on physical activity. The neighborhood environment characteristics such as population density, connectivity, and land use mix are already shown to be relevant to walking/cycling for transports including Also, neighborhood comparison and correlational studies with nonmotorized transport outcomes give substantial evidence that residents from communities with higher density, greater connectivity, and more land use mix report higher rates of walking/cycling for utilitarian purposes than low-density, poorly connected, and single land use neighborhoods. The transportation, urban design, and planning literatures provide a valuable starting point for multidisciplinary research on environmental contributions to physical activity levels in the population (Saelens et al., 2003).

Environmental implications: American Lung Association (2001) reported that over the past three decades, an array of legislation with attendant regulations has been implemented to enhance the quality of the environment and thereby improve the public's health. It also reported that despite the many beneficial changes that have followed, there remained a disproportionately higher prevalence of harmful environmental exposures, particularly air pollution, 
for certain populations. These populations most often resided in urban settings, had low socioeconomic status, and included a large proportion of ethnic minorities. The disparities between racial/ethnic minority and/or low-income populations in cities and the general population in terms of environmental exposures and related health risks have prompted the "environmental justice" or "environmental equity" movement, which strives to create cleaner environments for the most polluted communities. Achieving cleaner environments will require interventions based on scientific data specific to the populations at risk; however, research in this area has been relatively limited. To assess the current scientific information on urban air pollution and its health impacts and to help set the agenda for immediate intervention and future research, the American Lung Association organized an invited workshop on Urban Air Pollution and Health Inequities held 22-24 October 1999 in Washington, DC. This report builds on literature reviews and summarizes the discussions of working groups charged with addressing key areas relevant to air pollution and health effects in urban environments. An overview was provided of the state of the science for health impacts of air pollution and technologies available for air quality monitoring and exposure assessment. The working groups then prioritized research needs to address the knowledge gaps and developed recommendations for community interventions and public policy to begin to remedy the exposure and health inequities.

The role of the local Public Health service: The central question is how the local public health services can influence urban development and urban renewal policies. In this case there is a need for a three-way cooperation between departments of urban planning and development, environmental affairs and health to devise basically three essential "instruments" which could lead to a new and defined role of health departments in urban development: environmental and health audits, local health profiles and "health promotion committees" or similar bodies for closer cooperation at the local level (Trojan et al., 1994). Literature reports indicate that the "new role" of local health services in urban planning and development is presently fulfilled only in a few pilot cases. The lack of basic requirements particularly in terms of resources, motivation and qualifications is the main cause for the inability to implement the three "instruments" on a broader level in local health services (Trojan et al., 1994). Vlahov et al. (2005) reported that the majority of the world's population will live in cities in the next few years and the pace of urbanization worldwide will continue to accelerate over the coming decades. While the number of megacities is projected to increase, the largest population growth is expected to be in cities of less than one million people. Such a dramatic demographic shift can be expected to have an impact on population health. Although there has been historic interest in how city living affects health, a cogent framework that enables systematic study of urban health across time and place has yet to emerge. The effect on health of urbanization is two-edged. On the one hand, there are the benefits of ready access to healthcare, sanitation, and secure nutrition, whilst on the other there are the evils of overcrowding, pollution, social deprivation, crime, and stress-related illness. In certain societal groups including less developed countries, urbanization also opens the door to hypertension, heart disease, obesity, diabetes and asthma (Godfrey \& Julien, 2005).

Conclusions: Irrespective of the presence of universities and colleges, the surrounding neighborhood communities continue to face formidable historic challenges to improving public health and general quality of life. However, reinvestment initiatives, changing demographics, and growth in urban areas are creating changes that offer new opportunities for improving health while requiring that health systems be adapted to residents' health needs (Andrulis, 2000). However, the surrounding neighborhood communities seem to be immuned to developmental influence of the universities and colleges. This state of affair seem to suggest that health care improvement in metropolitan areas will require setting local, state, and national agendas before the these communities can see the light of progress. Therefore, certain priorities must be put in place namely health care must reorient around powerful population dynamics, in particular, cultural diversity, growing numbers of elderly, those in welfare-workplace transition, and those unable to negotiate an increasingly complex health system (Andrulis, 2000). Also, communities and governments must assess the consequences of health professional shortages, safety net provider closures and conversions, and new marketplace pressures in terms of their effects on access to care for vulnerable urban populations; they must also weigh the potential value of emerging models for improving those populations' care. Finally, governments at all levels should use their influence through accreditation, standards, tobacco settlements, and other financing streams to educate and guide urban providers in directions that respond to urban communities' health care needs (Andrulis, 2000).

It is concluded that the local, state and Federal Governments should establish and enforce socioeconomic, educational and the health policies 
for redistribution of population, policies for revitalization of urban centers, and policies for decentralization of development, and measures to stabilize the population within cities (Salas, 1981). Health providers working with inner-city populations must consider an array of social, health, and environmental factors in their assessments of health problems. Many of the societal issues, which negatively impact health, such as poverty, lack of a universal health program, unemployment, violence, drugs, and other factors, can be corrected in our society only if the political will to do so is present. Health workers have a responsibility to advocate for programs and environments in which all citizens can maximize their full potential. Populations in urban areas who are at risk for disease, disability, and premature death make cities special places for focusing on the promotion of health and the prevention of disease (Shannon, 1990).

\section{REFERENCES}

Denise, Jacobs. Sustainability in Third Ward Development, Houston, Texas. Houston: Wiston Press, 2004.

Lynch, Damon. Third Ward Development: Historic Third Ward, 2004, Texas Southern University, 11 Nov., 2004. http://City of Houston Planning and Development

Maclaren, Donald. Planning and Development: The History of Third Ward, Houston: Pocket, 2004.

Lynch Tim, Creating Sustainable Development: Midwest Sustainability Center, 2004. Chicago State University.. http://www.weber.u.washington.edu/npcweb/Envi.htm l.

Galea S, Vlahov D. Urban health: evidence, challenges, and directions. Annu Rev Public Health. 2005; 26:341-65

Vlahov D, Galea S. Urbanization, urbanicity, and health. J Urban Health. 2002 Dec;79(4 Suppl 1):S1-S12.

Vlahov D, Gibble E, Freudenberg N, Galea S. Cities and health: history, approaches, and key questions. Acad Med. 2004 Dec;79(12):1133-8.

Moore M, Gould P, Keary BS. Global urbanization and impact on health. Int J Hyg Environ Health. 2003 Aug;206(4-5):269-78.

World Resources Institute; United Nations Environment Program UNEP; United Nations Development Programme UNDP Urbanization: the challenge for the next century. Finance Dev. 1996 Jun;33(2):50.

Galea S, Rudenstine S, Vlahov D. Drug use, misuse, and the urban environment. Drug Alcohol Rev. 2005 Mar;24(2):127-36.
Satterthwaite D.The impact on health of urban environments. Environ Urban. 1993 Oct;5(2):87-111

Tabibzadeh I, Liisberg E. Response of health systems to urbanization in developing countries. World Health Forum. 1997;18(3-4):287-93.

Lawrence RJ. Urban health: an ecological perspective. Rev Environ Health. 1999 Jan-Mar;14(1):1-10.

Rossi-espagnet A. Primary health care in the context of rapid urbanization. Community Dev J. 1983;18(2):104-19.

Rotibi A. Improving the urban environment. Afr Health. 1992 Nov;15(1):26.

Anderson RJ, Boumbulian PJ, Pickens SS. The role of U.S. public hospitals in urban health. Acad Med. 2004 Dec;79(12):1162-8.

Schteingart M, Saenz O. [Environment, health and urban poverty. A perspective for the study of human settlements] Demos. 1991;(4):28-9.

Northridge ME, Sclar ED, Biswas P. Sorting out the connections between the built environment and health: a conceptual framework for navigating pathways and planning healthy cities. J Urban Health. 2003 Dec;80(4):556-68.

Ritter L, Solomon K, Sibley P, Hall K, Keen P, Mattu G, Linton B. Sources, pathways, and relative risks of contaminants in surface water and groundwater: a perspective prepared for the Walkerton inquiry. J Toxicol Environ Health A. 2002 Jan 11;65(1):1-142

Fiscella K, Williams DR. Health disparities based on socioeconomic inequities: implications for urban health care. Acad Med. 2004 Dec;79(12):1139-47.

Ezzati M, Utzinger J, Cairncross S, Cohen AJ, Singer BH. Environmental risks in the developing world: exposure indicators for evaluating interventions, programmes, and policies. J Epidemiol Community Health. 2005 Jan;59(1):15-22.

Freudenberg N. Health promotion in the city: a review of current practice and future prospects in the United States. Annu Rev Public Health. 2000;21:473-503.

Guerra FA, Crockett SA. Overcoming the hurdles to providing urban health care in the 21st century. : Acad Med. 2004 Dec;79(12):1148-53.

McDade TW, Adair LS. Defining the "urban" in urbanization and health: a factor analysis approach. Soc Sci Med. 2001 Jul;53(1):55-70.

Talib R, Agus MR. Social problems and health in urbanization. Southeast Asian J Trop Med Public Health. 1992;23 Suppl 3:84-93. 
Mishra CP. Role of education with regard to environmental hygiene and promotional activities. Swasth Hind. 1996 Apr-May;40(4-5):68-71.

Mutatkar RK. Public health problems of urbanization. Soc Sci Med. 1995 Oct;41(7):977-81.

Phillips DR. Urbanization and human health. Parasitology. 1993;106 Suppl:S93-107.

McAvoy PV, Driscoll MB, Gramling BJ. Integrating the environment, the economy, and community health: a Community Health Center's initiative to link health benefits to smart growth. Am J Public Health. 2004 Apr;94(4):525-7.

Galea S, Freudenberg N, Vlahov D. Cities and population health. Soc Sci Med. 2005 Mar;60(5):1017-33.

Emmanuel R. Urban vegetational change as an indicator of demographic trends in cities: the case of Detroit. Environ Plann B Plann Des. 1997 May;24(3):415-26.

Salas RM. Population and the urban future. Draper Fund Rep. 1981 Dec;(10):1-4.

Shaw RP. The impact of population growth on environment: the debate heats up. Environ Impact Assess Rev. 1992 Feb;12:11-36

Saelens BE, Sallis JF, Frank LD. Environmental correlates of walking and cycling: findings from the transportation, urban design, and planning literatures. Ann Behav Med. 2003 Spring;25(2):80-91.

Andrulis DP. Community, service, and policy strategies to improve health care access in the changing urban environment. Am J Public Health. 2000 Jun;90(6):858-62.
Shannon IR. Urban health: challenges and opportunities. Henry Ford Hosp Med J. 1990;38(2-3):144-7.

Fleischman AR, Barondess JA. Urban health: a look out our windows. Acad Med. 2004 Dec;79(12):1130-2.

Camp SL. Population pressure, poverty and the environment. : Integration. 1992 Jun;(32):24-7.

Guest P. Urbanization and its implications for health services. Warasan Prachakon Lae Sangkhom. 1998 Jul;7(1):21-52.

Altarejos RG. Urbanization in 21st century. Popul Forum. 1990;(1):9-10.

American Lung Association. Urban air pollution and health inequities: a workshop report. Environ Health Perspect. 2001 Jun;109 Suppl 3:357-74.

Trojan A, Stumm B, Suss W. [Role of the public health (and environmental) office in urban development-current status and perspectives] Gesundheitswesen. 1994 Oct;56(10):498-504.

Barron P, Lewin S, London L, Rumbelow R, Seager J, Truter $\mathrm{H}$. The state of housing, water and sanitation in the greater metropolitan area of Cape Town, 1995: report of a survey on access to basic subsistence facilities. Urban Health Newsl. 1996 Sep; (30):56-65.

Vlahov D, Galea S, Gibble E, Freudenberg N. Perspectives on urban conditions and population health. Cad Saude Publica. 2005 May-Jun;21(3):949-57. Epub 2005 May 2.

Godfrey R, Julien M. Urbanisation and health. Clin Med. 2005 Mar-Apr;5(2):137-41. 